\title{
Comparing The Impact Of An Astronomy Course And A Science And Society Seminar On Undergraduate Students' Attitudes Toward Science
}

\author{
Hélène M. L. G. Flohic, University of the Pacific, USA
}

\begin{abstract}
A common challenge among university professors is how to best design undergraduate courses to successfully enhance students' attitudes. To compare which curriculum was more efficient at fostering a positive attitude towards science in general, I studied the impact of two different general education science courses on the attitudes of college students. The first course was an arithmetic-based Introductory Astronomy course for non-science majoring undergraduates that used interactive and inquiry-based teaching techniques. The comparison course was a Science, Technology, \& Society (STS) seminar with context-based science contents, discussions, and intensive reading and writing. The postsemester results showed that neither curriculum on its own significantly changed the overall attitude of students towards science as far the assessment could measure, but that each curriculum did successfully enhance specific aspects of the students' attitude in differing categories. The STS students had scores showing a gain in believing that scientists are honest. The astronomy students had scores showing a gain in understanding that scientific theories can change in the light of new evidence. However, the most significant change was a loss in the astronomy students' confidence that the general public can and should understand science. Thus, the results suggest that professors who strongly desire to enhance the broad nature of students' attitudes need to use more purposeful instructional experiences rather than rely only on students' deepening understanding of the specific scientific content.
\end{abstract}

Keywords: Astronomy Education; Affect and Attitudes

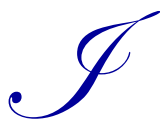

t has long been tacitly assumed that if students understand scientific content sufficiently well, then students will naturally exhibit positive attitudes, interest, and value in science. To the contrary, systematic research consistently suggests that schools and universities more often than not actually extinguish students' interest in science and lead to a decline in positive attitude (Osborne, Simon \& Collins, 2003). Indeed, many studies find that college students suffer a loss in attitude towards science after a semester-long science class. Garcia and McFeeley (1978) find that both science and non-science majors had a decrease in positive attitude after a semester of biology. Similarly, Rogers and Ford (1997) find that learning more science did not improve biology students' attitude. Redish, Saul and Steinberg (1998) find that a semester of introductory physics leads to a deterioration in all students' belief that physics relates to their everyday life and in two thirds of the students that physics is a coherent science. At best, semester-long science courses without intervention have no impact on the students' attitudes towards science (Marx \& Cummings, 2007; Zeilik, Schau \& Mattern, 1999)

DeBoer (2000) enthusiastically argues that purpose of understanding science and technology is not just for the sake of learning, but rather to enable and motivate citizens to contribute to and engage in society. Given how scientific advances and discoveries permeate our everyday lives, his argument is that schools and universities would be well advised to teach a basic knowledge in science and ignite and reinforce a desire to engage with science. Thus, the negative impact of college science courses is at odds with national calls for reform intended to instill students with the motivation to understand the science of issues directly related to their lives and well-being, and the confidence in their ability to do so. 
Attitude is a positive or negative stance, opinion or evaluation about just about anything: people, objects, events, activities, and ideas. One can have a positive attitude about something without being interested in it; however, we tend to have positive attitudes about things that interest us. (Fortus, 2014). Fishbein and Ajzen (1975) define attitude as a "'earned predisposition to respond in a consistently favorable or unfavorable manner towards an [...] object'. Since attitudes are learned, they can change (Koballa, 1988) and be influenced by a person's life experience (Fishbein \& Ajzen, 1975). However, attitudes take a long time to shift and are 'not momentarily transient' (Koballa, 1988).

The way science is taught is a factor in students' attitudes. In their systematic review of the literature, Potvin and Hasni (2014) identify the three main pedagogical factors that positively impact K-12 students' attitudes towards science: an encouraging and enthusiastic teacher, collaborative hands-on class work, and linking science and technology to reality. Several studies have tested specific curriculum changes aiming to foster a positive attitude among college students and align with Potvin and Hasni (2014)'s findings for K-12 students. Wittman (2009) showed that interactive in-class activities that promote thinking could have a positive impact on astronomy students' attitudes. Etkina and Mestre (2004) propose the use of controversial issues in biology courses to help the students consider their preconceptions about science-related topics, and to promote discussions about the process of science and the implications of scientific discoveries. Machina and Gokhale (2010) investigated the influence of science and technology (STS) seminars on first-year female students' attitude. They find that seminars that included visit from professionals and context-based content helped the students maintain a modestly positive attitude while seminars that did not include any of these interventions lead to a strong decline in attitude.

The interventions recommended and proven to positively impact student attitudes towards science all center on contextualization. Science education has been accused of being too abstract and detached from real-life existence (Krapp \& Prenzel, 2011). For example, Häussler and Hoffmann (2000) point to the overuse of idealized mathematical models and the excessive concentration on science and technology as a body of knowledge and procedures. Hands-on experience and integrated curricula serve to reassert science as human endeavor that attempts to better understand the world students live in (Potvin \& Hasni, 2014).

Most extant investigations examined the effects of contextualization on student attitudes in the elementary grades rather than at the secondary or college level (Guzzetti \& Bang, 2010; Potvin \& Hasni, 2014, and references therein). Moreover, the majority of studies tests one contextualization method rather than compares proposed curricular changes. What is most needed now is a research study that compares the impact of different contextualization methods at the college level. This study compares the influence of two methods of contextualization on the attitudes of college students: a Science, Technology, and Society (STS) seminar with professional visits and context-based content, and an introductory astronomy course with interactive in-class activities. First, I provide information about the tested curricula, the subjects in the study, and the instruments used in this study. Then, I explain the analysis method and present the results. Finally, I discuss the lessons learned from the results, summarize the conclusions, and provide future avenues of studies.

\section{METHOD}

Since Potvin and Hasni (2014) identified enthusiastic teachers, collaborative hands-on class work, and linking science to reality as the main pedagogical factors that influence student attitude towards science in K-12, I endeavored to determine which of collaborative interactive class work and linking science to student everyday life had the biggest impact on college students' attitude. To do so, I designed two courses, each using one the recommended pedagogical method. The first was an introduction to astronomy course with collaborative hands-on activities, the other a STS seminar that explicitly linked science to several aspect of the students' everyday life.

I taught both of these courses to general education students in Fall 2014 at the University of the Pacific. Since these courses had the same instructor, it removed one of the pedagogical variables. As a control group, I used the students enrolled in a general education seminar taught at the same time by another science professor. The control course did not cover science explicitly in its curriculum thus I did not expect any change in the attitude towards science for the control group. 
I gathered the syllabus, teaching notes, assessments, and course material for these courses in order to extract their aim, design, and outcomes, as presented in the Results section. I also performed a Teaching Practice Inventory (Wieman \& Gilbert, 2014, TPI) in order to evaluate the extent of use of research-based teaching practices (more information on the TPI can be found in the 'Instruments' subsection).

\section{Participants}

The subjects were the students enrolled in the three general education courses at the University of the Pacific during Fall 2014: Introduction to Astronomy, a STS seminar, and a general seminar. These three courses were selected because their pedagogies were different from one another while their students were all general education students thus I assumed that they would be similar to one another. One caveat is that the students in the seminars had been randomly assigned to a seminar while the students enrolled in the astronomy course had elected to take this specific course as a science general elective class to fulfill a curricular requirement.

Of the 23 students enrolled in the astronomy course, 21 volunteered to participate in the study and were at least 18 years of age. 15 of these 21 students were non-STEM majors, and 6 were majoring in a STEM field. The volunteers in this course consisted of 8 sophomores, 10 juniors, and 3 seniors. 12 were women and 9 were men.

Of the 18 students enrolled in the STS seminar, 17 volunteered to participate in the study and were at least 18 years old. 12 of these 17 participants were majoring in a STEM field and 5 were not. One student was a sophomore and all the others were freshmen. 5 were women and 12 were men.

Of the 19 students in the general seminar, 15 volunteered to participate in the study and were at least 18 years of age. All these students were freshmen majoring in STEM field. 5 were women and 10 were men.

In order to determine whether the student populations were comparable, at the end of the survey testing their attitude towards science, the students were asked to identify their class status (freshman, sophomore...), their gender, and whether they were a STEM major. The comparison of the student populations is presented in the Results section.

\section{Assessment Instruments}

During the first week of class, the students were given a link to an online survey, which was to be filled on a voluntary basis. The survey started with a consent form as required by the Internal Review Board. The students were informed that the survey results would be anonymized for the analysis and that I would not have access to the survey results until the following semester. I administered the Science Attitude Inventory II with permission of the authors (SAI II; Moore \& Foy, 1997). This instrument consists of 40 attitude statements assessed on a Likert scale ranging from 1 (strongly disagree) to 5 (strongly agree). The questions fall into 6 categories of questions as listed in Table 1. Each category of questions has an equal number of positive and negative statements.

During the last week of the semester, the students were asked to fill the SAI II again. The students were also asked for their gender, their major, and their college status (freshman, sophomore) for statistical purposes. The pre-semester surveys and post-semester survey were then matched using the student ID number. Students who had not taken both the pre-semester and post-semester surveys were dropped from our analysis.

In order to evaluate the extent of use of research-based teaching practices in each course, I used the Teaching Practice Inventory (Wieman \& Gilbert, 2014, TPI). The TPI lists 72 best practices to check off if they are practiced in class. These best teaching practices fall in eight categories: course information provided, supporting materials, in-class features and activities, assignments, feedback and testing, training and guidance of TAs, collaboration or sharing in teaching, and other. The maximum score is 67 and Wieman and Gilbert (2014) found TPI scores ranging from 10 to 50 in 179 courses in five science and mathematic departments used for their validation study. 


\section{Introductory Astronomy Course}

The first of the courses examined for this study was an introductory astronomy class for non-science majoring undergraduate students, which provided an in-depth look at the physics of stars and galaxies. Based on its syllabus, the aims of this course were for the students "to understand the powerful tools that astronomers have at their disposal, [...] learn how astronomers piece together the life history of a star [...], study [...] how [galaxies] form and interact, and [...] discuss the evidence that supports the Big Bang theory." In order to achieve its goals, the course had three major units: (1) the tools of astronomy (physics laws, interaction of light and matter, telescopes), (2) the life of stars, and (3) galaxies and cosmology.

The astronomy curriculum indirectly targeted categories 1, 2, and 3 of the SAI II. For example, during the cosmology unit, students learned that the acceleration of the expansion of the Universe was a recent and wholly unexpected discovery, which has yet to be fully explained and understood (Riess et al. 1998). This demonstrates that theories are subject to change, that observations are the basis of scientific exploration, and that scientists alter their position based on sufficient evidence. None of the category statements were specifically mentioned, but several such examples pertinent to the first three categories of the SAI II were mentioned during the semester. The astronomy curriculum also indirectly targeted category 5 of the SAI II by involving students in scientific thinking and labs.

Each class session started with a set of learning objectives listed as questions on a PowerPoint slide. These learning objectives were a subset of the learning objectives found in the textbook for the course "The Cosmic Perspective: Star, Galaxies, \& Cosmology" (Bennett, Donahue, O., Schneider, Nicholas \& Voit, 2013) and were aligned with one of the course aims. For example, the list of questions for the interactions of light and matter (covered on Sep 10 and Sep 15) were "What is light? What is the electromagnetic spectrum? What is the structure of matter? How is energy stored in atoms? How do light and matter interact?". These questions were then addressed and answered through lecture and interactive activities such as think-pair-share (Prather, Rudolph \& Brissenden, 2009), lecture tutorials (De Jong, 2005), demonstrations, and labs.

Continuous low-stakes assessments were carried out every class session through non-graded multiple-choice questions. Medium-staked formative assessments were also carried out through six homework sets (each worth 50 points for $10 \%$ of the course grade), ten 10-minute open-notes quizzes (each worth 10 points for $10 \%$ of the course grade), and 14 labs (worth $25 \%$ of the course grade). The lowest quiz and lab grades were dropped. High-stake assessments consisted of two midterms and a final, all cumulative, for $50 \%$ of the course grade. The midterms' and final's scores consisted of $80 \%$ multiple-choice questions testing the first four levels of the revised Bloom taxonomy (Anderson et al. 2000) and 20\% open-ended questions testing the levels three through five of the revised Bloom taxonomy. The students were allowed a midterm do-over in order to improve the formative nature of the assessments. The rest of the course points were for participation and were self-assessed by the students on a weekly basis.

The astronomy course had a TPI score of 34 out of 67 possible points, which is close to the average score of most science departments (Wieman \& Gilbert, 2014). 
Table 1. Categories of attitudes towards science tested by the SAI II survey.

\begin{tabular}{c|l}
\hline $\begin{array}{c}\text { Category } \\
\text { Number }\end{array}$ & \multicolumn{1}{c}{ Category statement } \\
\hline 1 & The laws and/or theories of science are approximations of truth and are subject to change. \\
\hline 2 & $\begin{array}{l}\text { Observation of natural phenomena and experimentation is the basis of scientific exploration. } \\
\text { To operate in a scientific manner, one must display such traits as intellectual honesty, dependence upon objective } \\
\text { observation of natural events, and willingness to alter one's position on the basis of sufficient evidence. }\end{array}$ \\
\hline 4 & Science is an idea-generating activity. \\
\hline 5 & The public can understand science and it ultimately benefits from scientific work. \\
\hline Note: Each category includes 6 to 8 position statements graded on a Likert scale, and an equal number of positive and negative statements.
\end{tabular}

Note: Each category includes 6 to 8 position statements graded on a Likert scale, and an equal number of positive and negative statements.

\section{Science, Technology, and Society Course}

The second course studied for this comparison study was a freshman undergraduate seminar entitled "Science, Technology, and Society", in which the societal influence of science was discussed with only a general overview of the science relating to the discussion topic of the day. The instructor for this course was the same as for the introductory astronomy course (and is the author of this study). Based on its syllabus, the aims of the course were to explore "the critical tension between individual rights and social responsibilities as that tension manifests in issues such as identity, equality, and sustainability, among others." To meet its goals, the course was organized in four units: (1) the nature and process of science, (2) the interplay of science and society (quality of life, justice, and the economy), (3) the impact of science on individuals (identity, diversity, ethics, and religion), and (4) science and the future (science literacy, education, and policies). This course specifically targets the development of the students' reading, writing, and critical thinking skills.

Before each class session, students had to read 25-45 pages from 3-6 different sources, all revolving around a weekly theme. Readings were picked from 'Science and Society (A Longman Topics Reader')' (Grinnell, 2006), "Science, Technology and Society: An Introduction" (Bridgstock, Burch, Forge, Laurent \& Lowe, 1998), "Science for All American" (Rutherford, 1991), "Unscientific America. How Scientific Illiteracy threatens our Future" (Kirshenbaum, 2009), recent articles from major newspapers, and seminal essays (e.g., Huxley, Popper). Reading was assessed through low-stakes quizzes every 2-3 class sessions (e.g., "Who was used as an example in this article about diversity in science?"). These reading assessments accounted for $10 \%$ of the course grade. The theme of the day was then explored through interactive activities such as small group discussions, case studies, interviews with professionals, class debates, etc. Participation was self-assessed on a weekly basis and counted for $15 \%$ of the grade.

The STS seminar clearly addressed several categories of the SAI II. During the unit on the nature of science, students discussed how scientific theories are based on experimentation (category 2) and subject to change (category 1). Throughout the semester, students and instructors modeled and applied the scientific attitude to be willing to alter one's position based on evidence (category 3). During the unit on science and society, students discussed how science leads to new ideas (category 4) and how the public benefits from it (category 5). The only category not directly targeted by the curriculum of the STS seminar was category 6 ("I would like to do scientific work") since the goal of the STS seminar was for the students to appreciate the benefits of science to society in general, not to influence them in becoming STEM majors.

Various connections between science and the theme of the week were explored. For example, when discussing justice, students discussed how forensic science influences justice, how the judicial system restricts what scientists are allowed to do, and how social scientists study the justice system in order to uncover its limitations. The instructor guided the discussions and kept the students on task, but the discussion would often diverge from the original prompt based on the students' interests. If questions about specific science topics arose, students in the classroom contributed their knowledge, the instructor corrected any factual error (if she was proficient enough in the subject), and the students were encouraged to explore the topic further and report by the next class session. For example, in order to discuss science literacy, a short clip from "Jimmy Kimmel live" showed that most people were strongly opposed to Genetically 
Modified Organisms (GMOs), yet they did not know what GMO stood for. After a long discussion on GMOs, a student asked what MSG stood for and what it was. Many students in the class knew that MSG was often used in Asian cuisine and that some people wanted to avoid having it, but no student knew what MSG stood, nor what it was. The instructor knew that MSG stood for mono sodium glutamate, but nothing more. By the next class session, instructors and students had personally searched for information on MSGs and discussed what they had learned. This way, many scientific topics were brought up in connection with societal issues, but no topic was covered in depth during class unless students had expressed specific interest in it.

The main assessment method for this course was through writing, which counted for $65 \%$ of the course grade. One third of the writing grade was from four 1-2 page answers to writing prompts specifically designed to give the students practice in articulating an argument. Two thirds of the writing grade were from three 5-6 pages essays in which students further explored an idea brought up during class that they found of personal interest (e.g., the impact of GMOs on society, how technology changed personal interactions, how the car transformed our everyday lives...). These essays assessed all three skills targeted by the course (reading, writing, and critical thinking). Students peer-reviewed the final draft of three of their classmates' essays in order to improve their own writing skills and their peers'. These peer review comments were peer-graded and contributed to the last $10 \%$ of the course grade.

A long-term assessment of the writing skills of all the students enrolled in a freshman seminar in Fall 2014 is ongoing at the university level. The first 1-2 page writing of the students was collected; students will be asked to write an essay answering a similar prompt during their senior seminar in 2017-2018. These will be used to assess the improvement in the students' writing skills.

Based on the information in the syllabus and the class notes used to guide the class sessions, I used the Teaching Practice Inventory (Wieman \& Gilbert, 2014) and found a score of 36 out of 67 possible points. Compared to the astronomy course, the STS seminar scored significantly higher on in-class features and activities, and worse on feedback and testing, while obtaining comparable scores in other teaching practices.

What is a good society? Course

To triangulate this data, another comparison course evaluated was a freshman seminar entitled "What is a good society?". This course had the same aims, grading scheme, and assessments methods as the STS seminar. However, it did not formally teach nor discuss science and thus served as our control group. Class meetings had the same type of interactive activities as the STS seminar thus this control seminar scored the same score of 36 out of 67 on the Teaching Practice Inventory.

The major differences in curriculum between the control seminar and the STS seminar were the choice of reading material and the essay prompts. The control seminar used "50 Essays: A Portable Anthology" (Cohen, 2013), "Born to Be Good: The Science of a Meaningful Life" (Keltner, 2009), and "Social: Why Our Brains Are Wired to Connect" (Lieberman, 2013). The themes explored through these readings were education, identity, race, gender, class, media, nature, ethics, and activism.

The students in this seminar are also evaluated on their long-term gain in writing skills as described for the STS seminar students.

\section{RESULTS}

I performed a Fisher exact test on the contingency table of the frequency of men and women in each course. I find a p-value of $1.2 \times 10^{-2}$, meaning that the student populations are significantly different in their gender distribution. This difference stems mostly from the large number of women enrolled in astronomy compared to the seminars. Thus, I included an analysis of the impact of gender on attitude towards science in a coming subsection.

I performed a Fisher exact test on the contingency table of the frequency of STEM majors in each course. I find a pvalue of $2.1 \times 10^{-6}$, meaning that the student populations are significantly different in their major distribution. Thus, in 
a coming subsection, I tested for differences in attitudes towards science between the STEM and the non-STEM students.

The distribution in class status is also significantly different given that the seminars have only freshman students while the astronomy course has no freshmen. For this reason, I also included an analysis of the difference in attitude as a function of class status for the astronomy course, which has a range in class status.

Attitudes towards Science - Impact of Course

Due to the small number of volunteers in each course, I did not perform an item-by-item analysis of the survey. Instead I performed an analysis over each category listed in Table 1 and over the whole survey. The averages and standard deviations of the pre-semester and post-semester surveys for each course are listed in Table 2 and the distributions of the scores for each course are shown in Figures 1 and 2.

The astronomy class has an overall lower average than the seminars both before and after the semester. To determine whether the difference in the distribution of responses was significant, I applied the Mann-Whitney test to the data. I used this test instead of the t-test because the data falls on an ordinal scale, not an interval scale, and because the distribution of responses is not a Gaussian distribution (as seen on Figures 1 and 2). I consider $p<0.05$ to be a significant difference. I find that the distribution of responses for the astronomy course is significantly different from the STS seminar $(\mathrm{p}=0.02)$, but I find no significant difference with the control seminar $(\mathrm{p}=0.07)$ and between the seminars $(\mathrm{p}=0.29)$. A comparison of the classes at the end of the semester finds that the attitude towards science of the astronomy students is still significantly lower than that of the STS seminar students $(p=0.03)$, but I find no difference with the control seminar $(\mathrm{p}=0.16)$ or between the seminars $(\mathrm{p}=0.15)$. 
Table 2. Survey results at the beginning and end of the semester for each course

\begin{tabular}{|c|c|c|c|}
\hline & Introductory astronomy & STS seminar & Control seminar \\
\hline \multicolumn{4}{|l|}{ All categories } \\
\hline Pre-semester & $3.55(1.10)$ & $3.68(0.98)$ & $3.66(0.94)$ \\
\hline Post-semester & $3.55(1.15)$ & $3.67(1.11)$ & $3.64(1.03)$ \\
\hline p-value & 0.42 & 0.32 & 0.44 \\
\hline \multicolumn{4}{|l|}{ Category 1} \\
\hline Pre-semester & $3.64(0.96)$ & $3.79(0.91)$ & $3.58(0.90)$ \\
\hline Post-semester & $3.85(1.09)$ & $3.80(1.18)$ & $3.57(0.95)$ \\
\hline p-value & 0.03 & 0.25 & 0.50 \\
\hline \multicolumn{4}{|l|}{ Category 2} \\
\hline Pre-semester & $3.77(1.01)$ & $3.59(1.02)$ & $3.42(0.95)$ \\
\hline Post-semester & $3.67(1.06)$ & $3.45(1.01)$ & $3.24(1.00)$ \\
\hline p-value & 0.20 & 0.16 & 0.13 \\
\hline \multicolumn{4}{|l|}{ Category 3} \\
\hline Pre-semester & $4.18(0.78)$ & $4.27(0.72)$ & $4.20(0.67)$ \\
\hline Post-semester & $4.22(0.88)$ & $4.44(0.70)$ & $4.20(0.82)$ \\
\hline p-value & 0.20 & 0.04 & 0.35 \\
\hline \multicolumn{4}{|l|}{ Category 4} \\
\hline Pre-semester & $3.00(1.00)$ & $3.04(1.20)$ & $2.87(1.03)$ \\
\hline Post-semester & $3.04(1.08)$ & $2.89(1.30)$ & $2.81(1.11)$ \\
\hline p-value & 0.38 & 0.20 & 0.33 \\
\hline \multicolumn{4}{|l|}{ Category 5} \\
\hline Pre-semester & $3.90(0.84)$ & $3.85(0.92)$ & $4.03(0.70)$ \\
\hline Post-semester & $3.47(1.01)$ & $3.87(1.06)$ & $4.12(0.87)$ \\
\hline p-value & 0.002 & 0.31 & 0.15 \\
\hline \multicolumn{4}{|l|}{ Category 6} \\
\hline Pre-semester & $3.16(1.25)$ & $3.63(0.76)$ & $3.82(0.79)$ \\
\hline Post-semester & $3.24(1.5)$ & $3.62(0.87)$ & $3.83(0.82)$ \\
\hline $\mathrm{p}$-value & 0.25 & 0.34 & 0.46 \\
\hline
\end{tabular}

Note: For the pre-semester and post-semester surveys, I quote the average of that specific category/course combination along with the standard deviation in parenthesis. I also list the p-value of the Mann-Whitney test comparing the distributions of results at the beginning and end of the semester. I bolded $\mathrm{p}$-values that were statistically significant $(\mathrm{p}<0.05)$.

I note a similar ranking of the different categories (both at the beginning and end of the semester) from one course to the next with category 4 (science is an idea-generating activity) consistently ranked the lowest and category 3 (scientists are honest) always the highest.

In the following subsections, I investigate whether the discrepancy in overall attitude between the astronomy students and the seminar students before any intervention can be explained by the differences in gender, class status of the student populations, or the difference in major. 
Figure 1. Distribution of the answers to the SAI II at the beginning of the semester. The results for the astronomy students are represented by the dashed line, those for the STS seminar students by the solid line, and the control seminar by the dotted line. For each course, the attitude is mildly positive, but the distribution of answers for the astronomy class is significantly different and worse than that of the freshman seminar students.

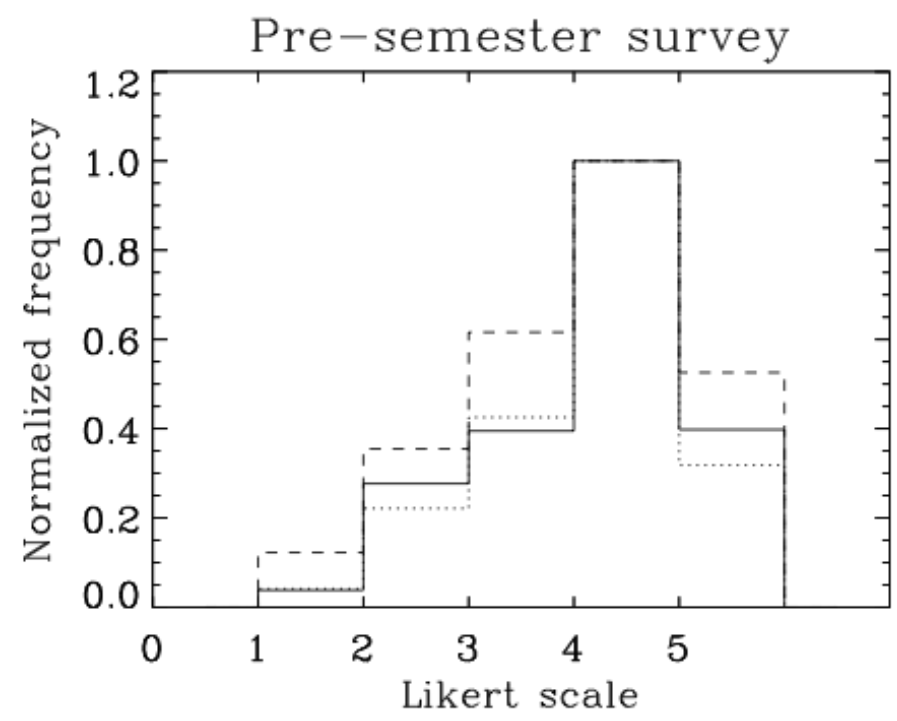

Figure 2. Distribution of the answers to the SAI survey at the end of the semester. The results for the astronomy students are represented by the dashed line, those for the STS seminar students by the solid line, and the control seminar by the dotted line. After a semester of instruction, the overall scores and distributions are unaffected.

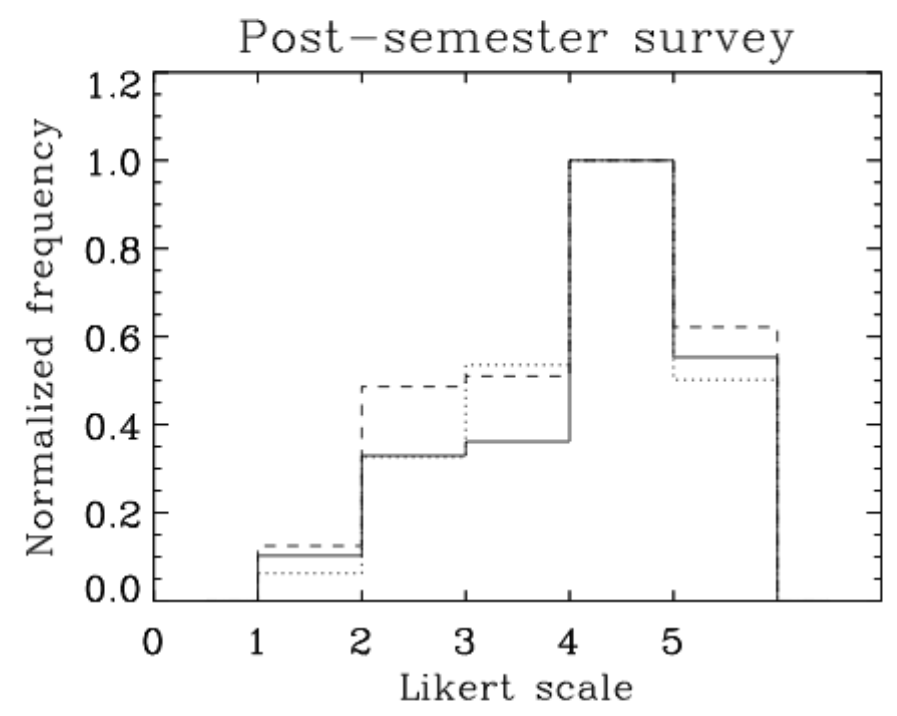

\section{Attitudes towards Science - Impact of Class Status}

The astronomy course was the only course whose students had a range of class status, from sophomore to senior. In order to determine whether attitudes towards science depend on the years of schooling in this course, I calculated the average SAI II scores for each year at the beginning of the semester. I find means and standard deviations of 3.60 
(1.07), 3.50 (1.06), and 3.56 (1.28) from sophomore to senior year. Note that the mean SAI II score is lowest for the juniors, meaning that there is no trend with schooling in this course.

I performed a Kruskal-Wallis test to the distribution of answers to the SAI II for the three subsamples of class status and find an $\mathrm{H}$ statistic of 1.93 and a one-tailed probability of 0.38 . This means that the distribution of answers to the SAI II does not vary significantly from year to year.

Finally, in order to compare the astronomy student population with the student population enrolled in the seminars, I compared the distribution of SAI II answers for the astronomy sophomore sample at the beginning of the semester with that of the control group at the end of the semester using a Mann-Whitney test. The control group did not receive any intervention so their attitude towards science at the end of their first semester in college should be comparable to that of general education sophomores at the beginning of the year. Indeed, I find a one tailed probability of 0.37, meaning that the attitude of sophomores starting astronomy is comparable to that of students at the end of their first semester in college. These tests thus dispel any doubt that the three populations of students may be different because of their numbers of years of schooling.

\section{Attitudes Towards Science - Impact of Gender}

Table 3 summarizes the average SAI II scores and standard deviations for the men and women in each course at the beginning of the semester. For each class in the study, I performed a Mann-Whitney test to compare the distribution of answers to the SAI II from men and women at the beginning of the semester; these results are also presented in Table 3.

Table 3. Survey results at the beginning of the semester for each course and for each gender

\begin{tabular}{l|c|c|c}
\hline & Introductory astronomy & STS seminar & Control seminar \\
\hline Men & $3.45(1.10)$ & $3.76(0.97)$ & $3.57(0.91)$ \\
\hline Women & $3.63(1.08)$ & $3.55(0.95)$ & $3.67(1.02)$ \\
\hline p-value & $\mathbf{0 . 0 0 9}$ & $\mathbf{0 . 0 0 3}$ & 0.051 \\
\hline
\end{tabular}

Note: I quote the average SAI II score for each group along with the standard deviation in parenthesis. I also list the p-value of the Mann-Whitney test comparing the distributions of results of men and women. I bolded p-values that were statistically significant $(\mathrm{p}<0.05)$.

There is no significant difference between the attitude of men and women in the control group (Figure 3), but there are significant differences in the other two courses: the women in astronomy score significantly higher than the men (Figure 4), while the men in the STS seminar score significantly higher than the women (Figure 5). Thus there is no systematic impact of gender on attitude towards science in the study. Since there is no significant difference in the control group, where all the students are majoring in a STEM field, I investigated whether the opposite attitudes of the men and women enrolled in astronomy and the STS seminar relate to differences in major. For each class, I performed a Fisher exact test on the contingency table of the frequency of STEM majors in each gender. I find pvalues of 0.33 and 0.28 for the astronomy and STS students respectively. Thus I did not detect a correlation between the difference in attitude between men and women and the students' major.

Since the male and female populations are significantly different in two courses, I analyze the impact of pedagogy on each gender in a coming subsection. 
Figure 3. Distribution of the answers to the SAI II at the beginning of the semester for the women (solid line) and men (dashed line) in the control group.

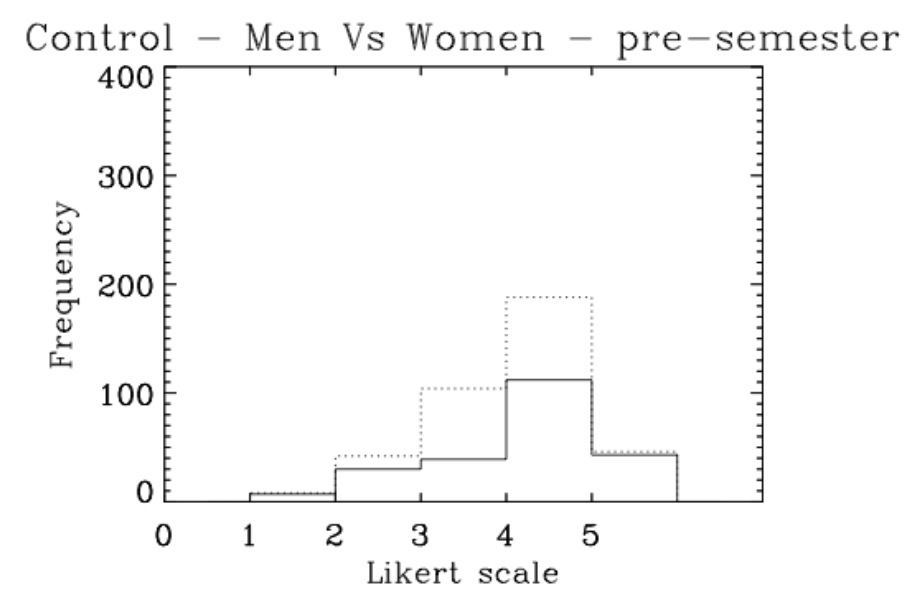

Figure 4. Distribution of the answers to the SAI II at the beginning of the semester for the women (solid line) and men (dashed line) in the astronomy class.

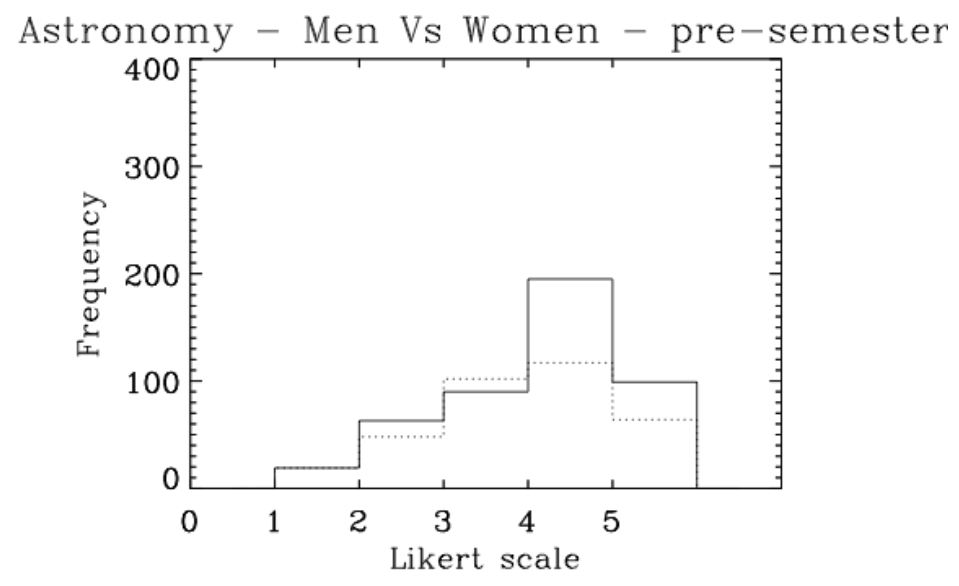


Figure 5. Distribution of the answers to the SAI II at the beginning of the semester for the women (solid line) and men (dashed line) in the STS seminar.

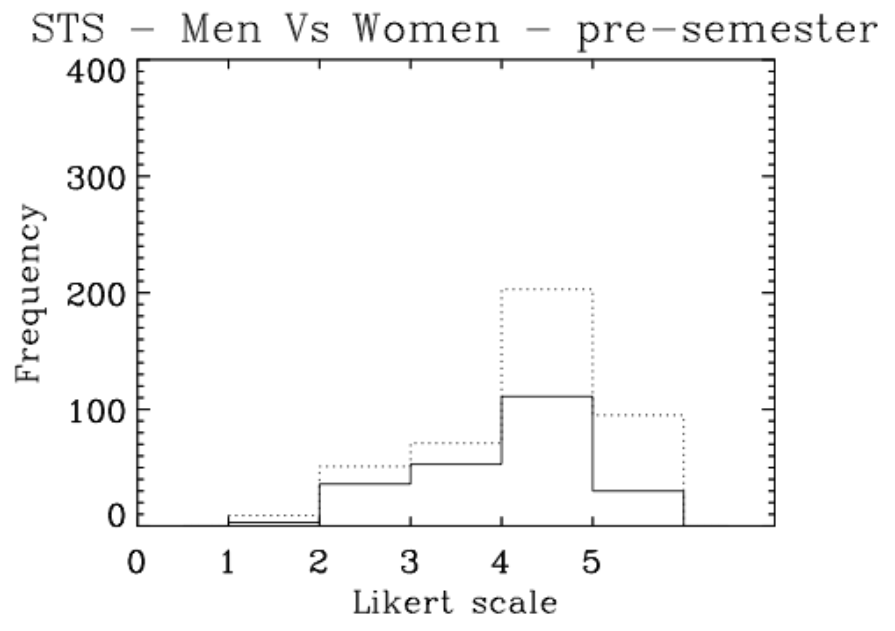

Attitudes Towards Science - Impact of Major

Table 4 summarizes the average SAI II scores and standard deviations for the STEM and non-STEM majors in astronomy and in the STS seminar. The control seminar is not included in this table because it was composed exclusively of STEM students. For each class in the study, I performed a Mann-Whitney test to compare the distribution of answers to the SAI II from STEM and non-STEM majors at the beginning of the semester; these results are also presented in Table 4.

There is no significant difference between STEM and non-STEM students in the STS seminar. The STEM majors enrolled in astronomy have a significantly worse attitude towards science than the non-STEM majors (Figure 6). Because of this, in the following section, I analyze the impact of pedagogy on students according to their majors.

Table 4. Survey results at the beginning of the semester for the STEM and non-STEM students

\begin{tabular}{l|c|c}
\hline & Introductory astronomy & STS seminar \\
\hline STEM & $3.46(0.96)$ & $3.72(0.96)$ \\
\hline Non-STEM & $3.59(1.15)$ & $3.59(1.03)$ \\
\hline p-value & $\mathbf{0 . 0 1}$ & 0.11 \\
\hline
\end{tabular}

Note: The control seminar is not included in this table because it was composed exclusively of STEM students. I quote the average SAI II score for each group along with the standard deviation in parenthesis. I also list the p-value of the Mann-Whitney test comparing the distributions of results of men and women. I bolded $p$-values that were statistically significant $(p<0.05)$. 
Figure 6. Distribution of the answers to the SAI II at the beginning of the semester for the STEM (solid line) and non-STEM students (dashed line) in the astronomy class.

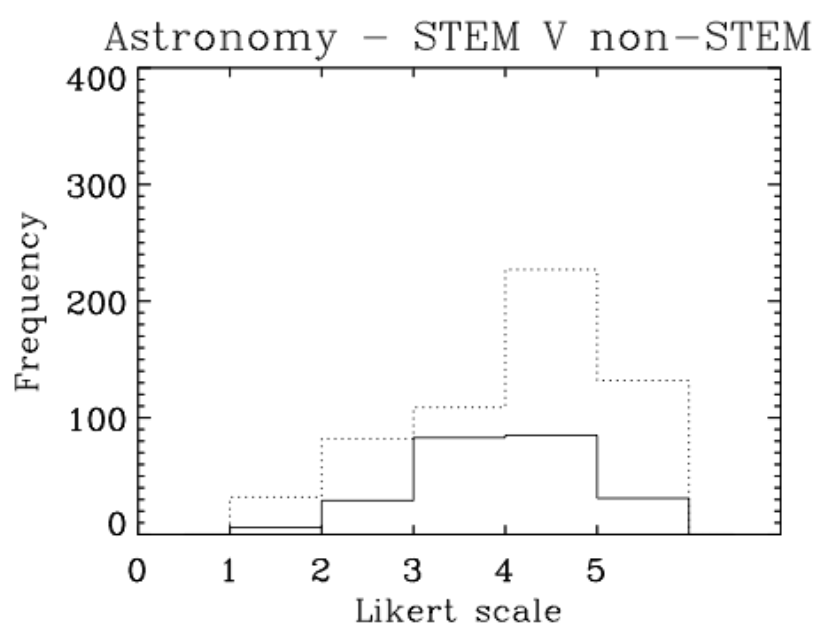

Attitudes towards Science - Impact of Pedagogy

I applied the Mann-Whitney test to determine whether the attitude towards science of each course had changed after a semester of instruction. The results of the Mann-Whitney tests for the whole classes are reported in Table 2. When considering the whole survey, I find no change in the distribution of survey results, indicating that taking an astronomy course or STS seminar does not impact the students' attitude one way or another. However when looking at the change in the different categories listed in Table 1, I see a significant change $(\mathrm{p}<0.05)$ in three category/course combinations. The STS seminar students have had a significant gain in thinking that scientists are honest and alter their position in view of sufficient evidence (category 3 ). The astronomy students had a significant gain in knowing that the laws and theories of science are approximations and subject to change (category 1). Finally, the most significant change was a loss in the astronomy students' belief that the public can understand science and benefit from scientific work (category 5). The histograms showing the pre-semester distribution and post-distribution of category/course with significant impact are shown in Figures 7 to 9. 
Figure 7. Distribution of the answers in category 3 for the STS seminar students. at the Category 3 is "To operate in a scientific manner, one must display such traits as intellectual honesty, dependence upon objective." The dotted line shows the distribution of answers at the beginning of the semester and the solid line the end of the semester. A significant improvement $(p<0.05)$ is noted.

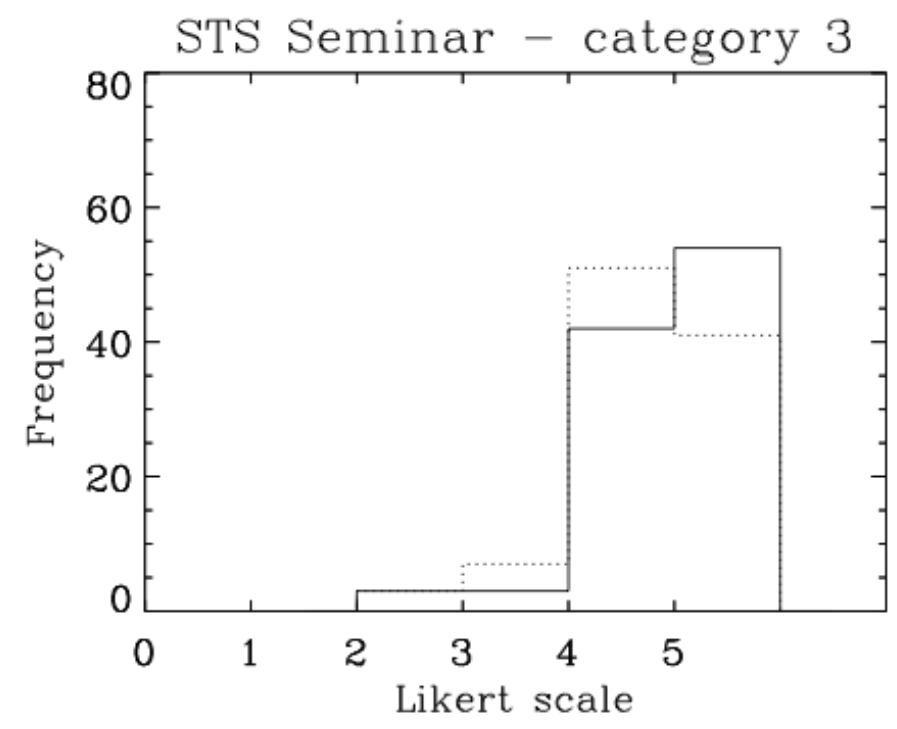

In order to understand whether one subpopulation of student is more affected than another, I show the results of the SAI II at the beginning and end of the semester broken down by major and gender in Tables 5 and 6 respectively. When the results are broken down by gender, the only significant change in attitude is detected in category 5 (the public can understand science) for both genders in astronomy. When looking at the impact of pedagogy depending on the major of the students, non-STEM students are driving the significant changes detected for the whole population of astronomy students in categories 1 and 5 while there is no significant impact of the pedagogy on the attitude of STEM students in any category. Differently, the STEM students are driving the change in attitude in category 3 for the STS seminar while the attitude of non-STEM students is not significantly impacted. 
Figure 8. Distribution of the answers in category 1 for the astronomy students. Category 1 is "The laws and/or theories of science are approximations of truth and are subject to change". The dotted line shows the distribution of answers at the beginning of the semester and the solid line the end of the semester. A significant improvement $(p<0.05)$ is noted.

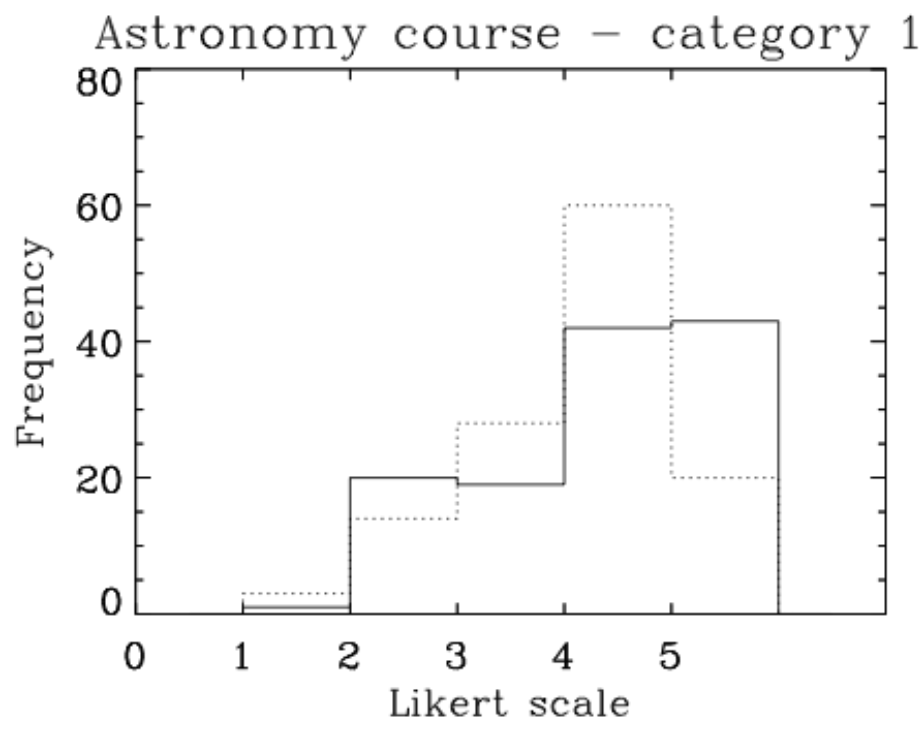

Figure 9. Distribution of the answers in category 5 for the astronomy students. Category 5 is "The public can understand science and it ultimately benefits from scientific work". The dotted line shows the distribution of answers at the beginning of the semester and the solid the end of the semester. A significant loss $(\mathrm{p}<0.05)$ is noted.

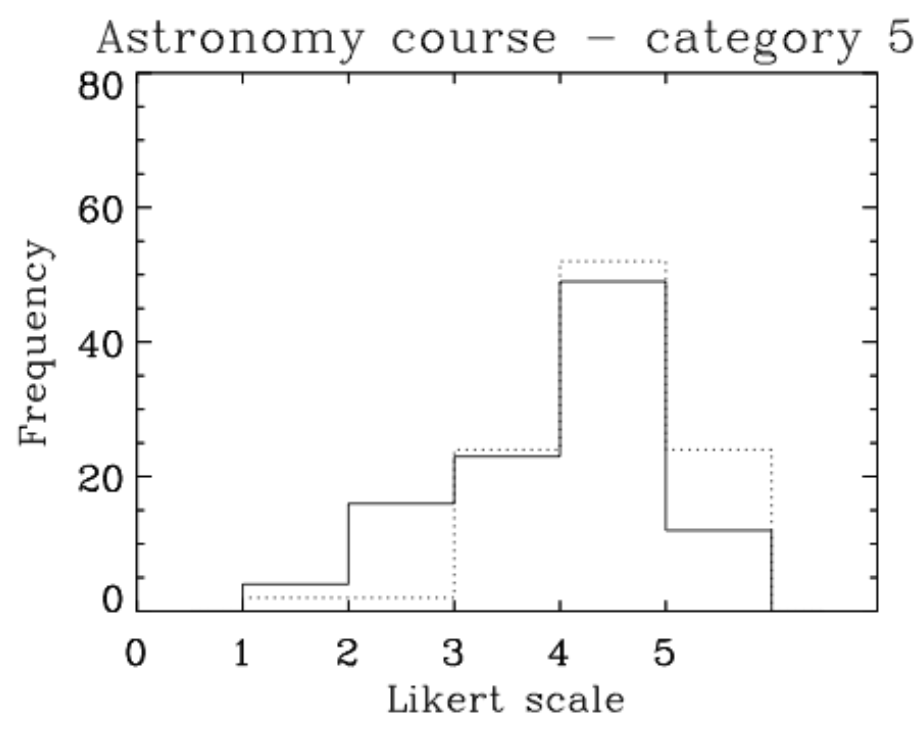




\section{DISCUSSION}

The students enrolled in astronomy exhibited significantly lower attitude scores towards science at the beginning of the semester. After careful analysis, this discrepancy with the other two classes cannot be attributed to class status since there is neither trend nor any significant change with years of instruction. This discrepancy cannot be attributed to the different gender ratio either: there are significantly more women enrolled in astronomy than in the other two courses, yet the attitude of the women in astronomy is significantly better than that of the men. Finally, it is hard to attribute the worse attitude of the astronomy students to a difference in major: while there are more non-STEM majors enrolled in astronomy, they have a better attitude than the astronomy STEM majors. Thus the astronomy population's worse attitude cannot be explained by the factors considered in this study. This discrepancy could reflect the fact that the population of students that chooses astronomy as a general education elective is less interested in science than a randomly selected group of students assigned to a freshman seminar. General education students might choose astronomy as their general elective since they view it as one of the easiest and more interesting science (Fraknoi, 1996).

The overall attitude of the undergraduate students in the sample is positive. The average values of the survey are well above a neutral attitude of 2.5. A mildly positive attitude before the start of the semester of science education was also noted by Machina and Gokhale (2010). It is encouraging that, overall, students do have a positive attitude towards science. An analysis of the attitude of subpopulations in our sample find no change in attitude with years of schooling, which is contrary to many studies that find a decline with years of schooling (Osborne et al., 2003; Potvin \& Hasni, 2014, and references therein). These comparison studies were mostly carried out at the K-12 level, but studies of college students find that seniors have a more positive attitude towards science than lower class students (Craker 2006). I also find no systematic correlation between gender and attitude: one course has women with a more positive attitude, one course has men with a more positive attitude, and one course has equal attitude for men and women. This is uncharacteristic since women typically have a lower attitude towards science compared to men (Osborne et al., 2003; Potvin \& Hasni, 2014, and references therein).

For the three classes in this study, the SAI II revealed no change in the students' overall attitude towards science regardless of curriculum. As seen in Figures 1 and 2, the distribution of answers after the semester is similar to the distribution before the semester for each course. The lack of impact after a semester of astronomy with interactive activities is contrary to the findings of Wittman (2009), but in agreement with Zeilik et al. (1999). The lack of overall impact in the STS seminar is in agreement with the Machina and Gokhale (2010) study that found that maintaining a mildly positive attitude was the best result obtained with a STS seminar. However, it is in contrast with Lee and Erdogan (2007) who find a significant improvement in the development of more positive attitudes toward science for students in a STS course.

When looking in details at the attitude in specific categories of the SAI II, there are some slight changes. The STS seminar students had a significant improvement in their belief that scientists are willing to alter their view in light of new evidence (Figure 7). This change was significant for the STEM students. I posit that this positive change came from discussions with scientists during the seminar so that students were able to experience scientists admitting the limit of their knowledge and admitting when they had made a wrong statement in a field in which they were not experts. Other studies found similar positive outcomes to discussions with scientists (Schibeci, 1984). Despite the curriculum's focus on all the other categories of the SAI II, there was no significant change in any other category for the STS students.

The astronomy students had a significant improvement in category 1 of the SAI II: understanding that the laws and theories of science are approximations of truth and subject to change (Figure 8). This gain in attitude is most significant for non-STEM students. The astronomy students had the most significant change in category 5: a loss in their belief that the general public can and should understand science (Figure 9). This worsening in attitude is significant regardless of gender, but most significant for non-STEM students. This result is distressing because it means that the students' life-long interest in science was negatively impacted by a semester-long instruction of arithmetic-based astronomy, despite the interactive nature of the course. 
This negative impact could be due to the large curriculum covered during the semester and could benefit from a decrease in course content (Sundberg, Dini \& Li, 1994). This decrease in confidence could also stem from the inclusion in the curriculum of cosmology, a topic whose observational evidence are hard to interpret (Wallace, Prather \& Duncan, 2012) and that challenges students' philosophies and pushes their understanding to the limit (Kragh, 2012). In future iterations of this course, the course content will be decreased in the hope of bolstering students' confidence in their ability to understand science. Moreover, I will test the attitude towards science of the students throughout the semester, after each unit, in order to pinpoint which unit, if any, most negatively impacts the students' attitude.

If the goal of a university science course is to foster a life-long interest in science and a positive attitude towards science, then I argue that a STS seminar is less harmful than an astronomy course. As shown in this study, covering a field in depth might actually be detrimental to the students' confidence in their ability to understand science despite the implementation of a hands-on interactive curriculum. This impact is felt most deeply by non-STEM majors who constitute the majority of the general population and whose attitude is less likely to be altered through future interactions with scientific topics (Kragh, 2012).

Since attitudes take a long time to shift and are 'not momentarily transient' (Koballa, 1988), the mild changes in attitude detected in this study over the course of a semester may be not be detectable in the long term. However, the small shifts in attitude may also be amplified with time as the study participants choose to interact more or less with sources of scientific information based on how their attitude and interest were influenced by the science courses tested in this study. A follow-up of the attitude of the participants is necessary to address whether college science courses influence the long-term attitudes of college graduates. Thus, I will have a follow-up study of the participants and test their attitude a few years after graduation (circa 2020). The SAI II will again be given to the participants as well as questions on the factors that most influenced their attitude towards science during their time in college and since graduation. This information will be used to test whether the changes in attitudes detected in this study persist, or whether they have been amplified or eliminated with time.

Finally, curricula that offer both a broad overview of the societal impact of science and an in-depth look at a scientific subject might best serve the two main purposes of college science courses: fostering an interest in science and developing quantitative and critical thinking skills. Such courses require a cross-disciplinary approach and are not common offerings in college catalogs. In order to test whether a science course with both breadth and depth in content positively influences students' attitude in more categories, I will develop a cross-disciplinary general education science course on energy and test its impact on the students' attitude. 
Table 5. Survey results at the beginning and end of the semester for the STEM and non-STEM majors

\begin{tabular}{|c|c|c|c|c|}
\hline & $\begin{array}{c}\text { Introductory } \\
\text { astronomy STEM }\end{array}$ & $\begin{array}{c}\text { Introductory } \\
\text { astronomy non-STEM }\end{array}$ & STS seminar STEM & $\begin{array}{l}\text { STS seminar non- } \\
\text { STEM }\end{array}$ \\
\hline \multicolumn{5}{|l|}{ All categories } \\
\hline Pre-semester & $3.46(0.96)$ & $3.59(1.15)$ & $3.72(0.96)$ & $3.59(1.03)$ \\
\hline Post-semester & $3.42(1.10)$ & $3.60(1.18)$ & $3.72(1.13)$ & $3.54(1.05)$ \\
\hline p-value & 0.32 & 0.07 & 0.19 & 0.06 \\
\hline \multicolumn{5}{|l|}{ Category 1} \\
\hline Pre-semester & $3.64(0.68)$ & $3.64(1.06)$ & $3.72(0.89)$ & $3.97(0.96)$ \\
\hline Post-semester & $3.50(1.16)$ & $3.99(1.04)$ & $3.79(1.26)$ & $3.83(0.99)$ \\
\hline $\mathrm{p}$-value & 0.28 & 0.01 & 0.14 & 0.30 \\
\hline \multicolumn{5}{|l|}{ Category 2} \\
\hline Pre-semester & $3.37(0.94)$ & $3.92(1.00)$ & $3.64(1.01)$ & $3.47(1.04)$ \\
\hline Post-semester & $3.23(1.09)$ & $3.84(1.01)$ & $3.47(1.06)$ & $3.37(0.89)$ \\
\hline p-value & 0.30 & 0.29 & 0.19 & 0.33 \\
\hline \multicolumn{5}{|l|}{ Category 3} \\
\hline Pre-semester & $3.92(0.65)$ & $4.33(0.83)$ & $4.26(0.71)$ & $4.30(0.75)$ \\
\hline Post-semester & $3.72(1.09)$ & $4.33(0.72)$ & $4.50(0.65)$ & $4.30(0.79)$ \\
\hline p-value & 0.29 & 0.41 & 0.03 & 0.46 \\
\hline \multicolumn{5}{|l|}{ Category 4} \\
\hline Pre-semester & $2.89(0.89)$ & $3.04(1.04)$ & $3.13(1.17)$ & $2.83(1.26)$ \\
\hline Post-semester & $3.00(1.01)$ & $3.06(1.11)$ & $2.89(1.38)$ & $2.90(1.12)$ \\
\hline p-value & 0.40 & 0.44 & 0.13 & 0.38 \\
\hline \multicolumn{5}{|l|}{ Category 5} \\
\hline Pre-semester & $3.80(0.66)$ & $3.95(0.90)$ & $3.83(1.01)$ & $3.88(0.67)$ \\
\hline Post-semester & $3.60(0.97)$ & $3.42(1.03)$ & $3.87(1.03)$ & $3.88(1.013)$ \\
\hline p-value & 0.27 & 0.001 & 0.40 & 0.28 \\
\hline \multicolumn{5}{|l|}{ Category 6} \\
\hline Pre-semester & $3.30(1.20)$ & $3.10(1.26)$ & $3.75(0.70)$ & $3.34(0.82)$ \\
\hline Post-semester & $3.45(1.13)$ & $3.15(1.28)$ & $3.78(0.83)$ & $3.24(0.87)$ \\
\hline $\mathrm{p}$-value & 0.24 & 0.35 & 0.20 & 0.30 \\
\hline
\end{tabular}

Note: The results are shown for each category listed in Table 1. For the pre-semester and post-semester surveys, I quote the average of that specific category/course combination along with the standard deviation in parenthesis. I also list the p-value of the Mann-Whitney test comparing the distributions of results at the beginning and end of the semester. I bolded p-values that were statistically significant $(\mathrm{p}<0.05)$. 
Table 6. Survey results at the beginning and end of the semester for each course, broken down by gender

\begin{tabular}{|c|c|c|c|c|c|c|}
\hline & $\begin{array}{c}\text { Astronomy } \\
\text { Men }\end{array}$ & $\begin{array}{c}\text { Astronomy } \\
\text { Women }\end{array}$ & STS Men & $\begin{array}{c}\text { STS } \\
\text { Women }\end{array}$ & $\begin{array}{c}\text { Control } \\
\text { Men }\end{array}$ & $\begin{array}{l}\text { Control } \\
\text { Women }\end{array}$ \\
\hline \multicolumn{7}{|l|}{ All categories } \\
\hline Pre-semester & $3.45(1.10)$ & $3.63(1.08)$ & $3.76(1.00)$ & $3.55(0.95)$ & $3.57(0.91)$ & $3.67(1.02)$ \\
\hline Post-semester & $3.55(1.15)$ & $3.54(1.16)$ & $3.71(1.16)$ & $3.60(1.01)$ & $3.60(1.04)$ & $3.73(1.02)$ \\
\hline p-value & 0.09 & 0.18 & 0.41 & 0.27 & 0.27 & 0.27 \\
\hline \multicolumn{7}{|l|}{ Category 1} \\
\hline Pre-semester & $3.59(0.94)$ & $3.68(0.98)$ & $3.80(1.01)$ & $3.78(0.72)$ & $3.49(0.90)$ & $3.77(0.90)$ \\
\hline Post-semester & $3.83(1.06)$ & $3.86(1.15)$ & $3.86(1.25)$ & $3.70(1.04)$ & $3.46(0.97)$ & $3.80(0.89)$ \\
\hline p-value & 0.10 & 0.09 & 0.19 & 0.45 & 0.45 & 0.44 \\
\hline \multicolumn{7}{|l|}{ Category 2} \\
\hline Pre-semester & $3.59(1.05)$ & $3.90(0.97)$ & $3.67(1.04)$ & $3.44(0.97)$ & $3.37(0.91)$ & $3.50(1.04)$ \\
\hline Post-semester & $3.57(1.14)$ & $3.74(1.00)$ & $3.50(1.07)$ & $3.36(0.90)$ & $3.29(1.08)$ & $3.17(0.83)$ \\
\hline p-value & 0.50 & 0.18 & 0.19 & 0.36 & 0.35 & 0.07 \\
\hline \multicolumn{7}{|l|}{ Category 3} \\
\hline Pre-semester & $4.03(0.80)$ & $4.28(0.76)$ & $4.36(0.65)$ & $4.11(0.82)$ & $4.17(0.67)$ & $4.27(0.69)$ \\
\hline Post-semester & $4.15(0.94)$ & $4.28(0.83)$ & $4.51(0.56)$ & $4.31(0.89)$ & $4.20(0.80)$ & $4.20(0.89)$ \\
\hline p-value & 0.17 & 0.40 & 0.12 & 0.11 & 0.31 & 0.50 \\
\hline \multicolumn{7}{|l|}{ Category 4} \\
\hline Pre-semester & $2.80(0.90)$ & $3.15(1.05)$ & $3.28(1.20)$ & $2.69(1.14)$ & $2.88(0.99)$ & $2.77(1.22)$ \\
\hline Post-semester & $3.00(1.12)$ & $3.07(1.06)$ & $2.89(1.37)$ & $2.89(1.19)$ & $2.82(1.09)$ & $2.80(1.16)$ \\
\hline p-value & 0.17 & 0.32 & 0.08 & 0.25 & 0.37 & 0.49 \\
\hline \multicolumn{7}{|l|}{ Category 5} \\
\hline Pre-semester & $3.82(0.95)$ & $3.97(0.76)$ & $3.91(0.95)$ & $3.73(0.87)$ & $3.90(0.61)$ & $4.28(0.79)$ \\
\hline Post-semester & $3.43(1.00)$ & $3.50(1.03)$ & $3.84(1.10)$ & $3.93(0.98)$ & $4.06(0.91)$ & $4.24(0.78)$ \\
\hline p-value & 0.04 & 0.01 & 0.46 & 0.16 & 0.10 & 0.42 \\
\hline \multicolumn{7}{|l|}{ Category 6} \\
\hline Pre-semester & $3.16(1.28)$ & $3.17(1.22)$ & $3.65(0.82)$ & $3.58(0.65)$ & $3.62(0.81)$ & $4.22(0.58)$ \\
\hline Post-semester & $3.40(1.25)$ & $3.12(1.23)$ & $3.68(0.96)$ & $3.51(0.68)$ & $3.71(0.84)$ & $4.06(0.74)$ \\
\hline p-value & 0.09 & 0.38 & 0.24 & 0.40 & 0.22 & 0.19 \\
\hline
\end{tabular}

Note: For the pre-semester and post-semester surveys, I quote the average of that specific category/course combination along with the standard deviation in parenthesis. I also list the p-value of the Mann-Whitney test comparing the distributions of results at the beginning and end of the semester. I bolded $p$-values that were statistically significant $(p<0.05)$.

\section{AUTHOR BIOGRAPHY}

H. Flohic is an assistant professor of physics at the University of the Pacific in Stockton, CA. She obtained her B.S. in astronomy from the University of Florida in 2001 and her Ph.D. in astronomy and astrophysics from the Pennsylvania State University in 2008. Her doctoral work studied the structure of accretion disks around supermassive black holes. She was a postdoctoral researcher at the University of California, Irvine from 2008 to 2010 and a FONDECYT postdoctoral fellow at the Universidad de Chile from 2010 to 2013. E-mail: hflohic@pacific.edu

\section{REFERENCES}

Anderson, L. W., Krathwohl, D. R., Airasian, P. W., Cruikshank, K. A., Mayer, R. E., Pintrich, P. R., ... Wittrock, M. C. (2000). A taxonomy for learning, teaching, and assessing: A revision of bloom's taxonomy of educational objectives. Abridged Edition, New York: Pearson.

Bennett, J. O., Donahue, O., M., Schneider, Nicholas, \& Voit, M. (2013). The Cosmic Perspective: Stars and Galaxies (7th ed.). Reading, MA: Addison-Wesley.

Bridgstock, M., Burch, D., Forge, J., Laurent, J., \& Lowe, I. (1998). Science, technology and society: An introduction. Cambridge: Cambridge University Press.

Cohen, S. (2013). 50 essays: A portable anthology (4th ed.). New York: Bedford/St. Martin's.

Craker, D. (2006). Attitudes toward science of students enrolled in introductory level science courses at UW-La Crosse. $U W-L$ Journal of Undergraduate Research, 9, 1-6.

Deming, G., \& Hufnagel, B. (2001). Who's taking ASTRO 101?, The Physics Teacher, 39(6), 368-269. 
De Jong, M. L. (2005). Astronomy active learning in-class tutorials. Reading, MA: Addison-Wesley.

DeBoer, G. E. (2000). Scientific literacy: Another look at its historical and contemporary meanings and its relationship to science education reform. Journal of Research in Science Teaching, 37(6), 582-601.

Etkina, E. \& Mestre, J. P. (2004). Implications of learning research for teaching science to non-science majors. SENCER, Harrisburg, PA

Fishbein, M. A. \& Ajzen, I. (1975). Belief, attitude, intention and behavior: An introduction to theory and research. Reading, MA: Addison-Wesley.

Fortus, D. (2014). Attending to affect. Journal of Research in Science Teaching, 51(7), 821-835.

Fraknoi, A. (1996). The state of astronomy education in the US. Astronomical Society of the Pacific Conference Series, 89(1), 925.

Garcia, R. A. \& McFeeley, J. C. (1978). Proceedings of National Association of Biology Teachers Conference, Denver, CO: Attitude modification among biology and non-biology majors.

Grinnell, Richard, M. (2006). Science and society (A Longman Topics Reader). New York: Pearson.

Guzzetti, B. J. \& Bang, E. (2010). The influence of literacy-based science instruction on adolescents' interest, participation, and achievement in science. Literacy Research and Instruction, 50(1), 44-67.

Häussler, P. \& Hoffmann, L. (2000). A curricular frame for physics education: Development, comparison with students' interests, and impact on students' achievement and self-concept. Science Education, 84(6), 689-705.

Keltner, D. (2009). Born to be good: The science of a meaningful life. W. W. Norton \& Company.

Kirshenbaum, C. M. A. S. (2009). Unscientific America. How scientific illiteracy threatens our future. NY: Basic Books.

Koballa, T. R. (1988). Attitude and related concepts in science education. Science Education, 72(2), 115-126.

Kragh, H. (2012). Cosmology and Science education: Problems and promises. arXiv: 1212.1592

Krapp, A. \& Prenzel, M. (2011). Research on interest in science: Theories, methods, and findings. International Journal of Science Education, 33(1), 27-50.

Lee, M.-K. \& Erdogan, I. (2007). The effect of science, technology, society teaching on students' attitudes toward science and certain aspects of creativity. International Journal of Science Education, 29(11), 1315-1327.

Lieberman, M. D. (2013). Social: Why our brains are wired to connect. New York: Crown.

Machina, K. \& Gokhale, A. (2010). Maintaining positive attitudes toward science and technology in first year female undergraduates: Peril and promise. International Journal of Science Education, 32(4), 523-540.

Marx, J. \& Cummings, K. (2007). Proceedings of AIP Conference: What factors really influence shifts in students' attitudes and expectations in an introductory physics course? 883(1), 101-104.

Moore, R. W. \& Foy, R. L. H. (1997). The scientific attitude inventory: A revision (SAI II). Journal of Research in Science Teaching, 34(4), 327-336.

Osborne, J., Simon, S., \& Collins, S. (2003). Attitudes towards science: A review of the literature and its implications. International Journal of Science Education, 25(9), 1049-1079.

Potvin, P. \& Hasni, A. (2014). Interest, motivation and attitude towards science and technology at K-12 levels: A systematic review of 12 years of educational research. Studies in Science Education, 50(1), 85-129.

Prather, E. E., Rudolph, A. L., \& Brissenden, G. (2009). Teaching and learning astronomy in the 21 st century. Physics Today, $62(10), 41-47$.

Redish, E. F., Saul, J. M., \& Steinberg, R. N. (1998). Student expectations in introductory physics. American Journal of Physics, 66, 212-224.

Riess, A. G., Filippenko, A. V., Challis, P., Clocchiatti, A., Diercks, A., Garnavich, P. M. ... Tonry, J. (1998). Observational evidence from supernovae for an accelerating universe and a cosmological constant. The Astronomical Journal, 116(3), 1009.

Rogers, W. D. \& Ford, R. (1997). Factors that affect student attitude toward biology. Bioscience, 23(2), 3-5.

Rutherford, F. J. (1991). Science for all Americans (2nd ed.). Oxford: Oxford University Press.

Schibeci, R. A. (1984). Attitudes to Science: An update. Studies in Science Education, 11(1), 26-59.

Sundberg, M. D., Dini, M. L., \& Li, E. (1994). Decreasing course content improves student comprehension of science and attitudes towards science in freshman biology. Journal of Research in Science Teaching, 31(6), 679-693.

Wallace, C. S., Prather, E. E., \& Duncan, D. K. (2012). A study of general education astronomy students' understandings of cosmology. Part IV. Common difficulties students experience with cosmology. Astronomy Education Review, 11(1), 111.

Wieman, C. \& Gilbert, S. (2014). The Teaching Practices Inventory: A new tool for characterizing college and university teaching in mathematics and science. CBE - Life Sciences Education, 13(3), 552-569.

Wittman, D. (2009). Shaping attitudes toward science in an introductory astronomy course. The Physics Teacher, 47 9), $591-594$.

Zeilik, M., Schau, C., \& Mattern, N. (1999). Conceptual astronomy. II. Replicating conceptual gains, probing attitude changes across three semesters. American Journal of Physics, 67(10), 923-927. 